\title{
A controlled evaluation of a health education programme for pregnant women in rural areas
}

\author{
D ZMIROU, M CHARREL, AND C VEYRE \\ From the Centre Alpin de Recherche Epidémiologique et de Prévention Sanitaire, Chu, Pavillon D. BP 217 X 38043, \\ Grenoble Cédex, France
}

SUMMARY A controlled evaulation of health education for pregnant women was implemented from 1983 to 1985 in the French north alpine rural area with a quasi-experimental design. Altogether 116 villages (88983 inhabitants) constituted the pilot zone where the programme took place. This was matched with a control zone of 114 villages ( 78800 inhabitants) where routine antenatal surveillance was not changed. The programme involved a large group of health and social workers and institutions and several educational devices. There was a total of 3143 births to the study women during the programme. In all the 45 maternity clinics of the region the mothers were questioned as to their pregnancy history and delivery outcome. The programme succeeded in increasing, in the pilot zone, the proportion of women who benefited from a monthly antenatal visit, whereas no positive trend was shown in the control zones, even when controlling for some identified potential confounders (age and distance to health care providers). Similarly, women in the pilot zone were more likely to attend delivery preparation sessions than women in the control zone. However, many conditions revealed no differential modification in the two study zones. Perinatal morbidity is lower in the north alpine rural area than in the whole country. These results favour further development of social policies for pregnancy and of prenatal care, complemented by better information and training for health and social workers; they also favour better information as to medical monitoring, hygiene, and social rights related to pregnancy.

Perinatal mortality has declined dramatically in France during the last 15 years $^{1}$ as a result of prevention programmes involving specialised professional training, technological equipment of maternity hospitals, closing down of small maternity wards, and implementation of comprehensive social policies; it was also a result of general progress towards better education and living standards. However, much remains to be done to reduce inequalities among different segments of the population.

Limits are reached in the development of welfare state policies, and one cannot expect, in the long term, dramatic improvements of social policies and of perinatal health services availability. Thus, it is of great interest to evaluate the efficiency of prevention programmes whose goal would be-in a given social and medical context - to improve, in health workers, pregnant women, and the general population, their attitude towards general hygiene, use of medical care, and the way they benefit from existing social regulations.

In France, rural areas do not rank unfavourably in terms of perinatal mortality and morbidity. ${ }^{2}$ However, they offer specific conditions for the implementation of such policies ${ }^{3}$ : a lower density of health care providers, a high proportion of those social classesfarmers and other independent workers, such as merchants and craftsmen-whose social security is less comprehensive than that of salaried earners, importance of small enterprises where noncompliance with labour regulations is not uncommon, small towns and scattered dwellings where the communication networks differ markedly from that prevailing in large urban units.

The aim of this study was to assess the effect of a health education programme on some behavioural variables that influence the course and the outcome of pregnancy in the specific setting of rural areas in a developed country.

\section{Methods}

The programme took place between 1983 and 1985 in the northern alpine region of France, which comprises highly developed areas where tourism and industry employ a large proportion of the labour force, along with more traditional rural areas. The study 
had a quasi-experimental design. Among four Départements (counties), a pilot zone composed of 116 villages was matched with a control zone of 114 villages with respect to geographic, demographic, and socioeconomic characteristics and to availability of health services (table 1). The quasi-experimental design was chosen for two main reasons: (i) it was impossible to ask a physician or a social worker to behave differently according to the study group to which women were assigned; this allocation was done on a village basis; (ii) for practical and also strategic reasons, it was necessary to negotiate this allocation with the public health authorities and local professional workers involved in the programme; therefore a complete random allocation was not possible.

It took six months to set up the programme. This involved liaison with local social security and public health agencies and, most important, with representatives of those who were to be associated with the prevention procedures, ie, social workers, general physicians, and hospital obstetricians, among others. Local associations were also involved, such as family, farmers or women's rights associations.

The procedures relied essentially on four methods. Firstly, social workers visited at home all women whose pregnancy had been notified to social security agencies to deliver and explain a health education pamphlet and to complete short questionnaires. These visits generally took place during the fourth to sixth month of the pregnancy. Two other pamphlets complemented this information and were then mailed to each woman later on during the pregnancy. The items covered in these pamphlets dealt with the issues

Table 1 General description of the pilot and control zones before implementation of the educational programme (1982 data)

\begin{tabular}{lcc}
\hline Descriptive data & Pilot zone & Control zone \\
\hline Total population 1 & 88983 & 78800 \\
Total births & 1241 & 1061 \\
Number of villages & 116 & 114 \\
Average population of villages (sd) & $767(494)$ & $691(481)$ \\
Number of physicians ${ }^{2}$ within & 3.5 & 4.6 \\
Skm (average) & 19.6 & 19.6 \\
Mean distance to maternity clinic $(\mathrm{km})^{3}$ & &
\end{tabular}

General north alpine rural area data:

$\% 4$ Farmers 15.9

$\% 4$ Blue collar $37 \cdot 2$

\footnotetext{
1 Source: General census of the population 1982-Institut National des

Statistiques et des Etudes Economiques (INSEE)
Including GPs, OB/GYN and paediatricians. Source: Annual census of health professionals, 'Département' Public Health Agencies, 1982

3 Source: Inventaire communal-Indicateur chiffrés, 1979-1980-INSEE

$4 \%$ among active population; source: General census of the population 1982. INSEE
}

that were the most relevant to the stage of the woman's pregnancy. Altogether 136 social workers participated in this task. Secondly, all the private practitioners who had their practice in the pilot villages and within a $15 \mathrm{~km}$ area around the villages (ie, a total of about 200 GPs and obstetricians) were met individually and asked to contribute to the programme by answering their patients' questions arising from information contained in the pamphlets, and by participating in local meetings that were planned by the Protection Maternelle et Infantile Services (Mother and Child Health Public Services [MCHPS]). Thirdly, three colour slides were prepared and made available to all MCHPS within the pilot region, along with some educational films lent by private milk or drug companies. These audio visual aids were used in 83 meetings that were held in the pilot villages during the survey. In addition to general advertising (through local newspapers or posters), all the pregnant women within the area were invited to these meetings. The fourth method involved 50 occupational health physicians who worked in industry, shops, and other services within the pilot areas. They were asked to pay particular attention to the monitoring of pregnancies of women who were employed in the enterprises they visited, so that these women could benefit from the current labour regulations (reduction of work time, maternity leave, and avoidance of physical and chemical hazards). Complementing the work of these physicians, local associations were also involved in the general education programme.

The pilot and control villages were chosen far enough apart so that "contamination" of the control areas could be avoided. While this was successfully achieved as far as private physicians and local meetings were concerned, it was more difficult for the social workers and MCHPS whose administrative territories are larger. However, those professional workers did not deliver the educational pamphlets nor did they plan regular visits to pregnant women in control villages. The baseline "visit rate" prior to the programme was $10 \%$; it remained unchanged in the control population during the programme.

The evaluation of the programme used several sources of information. It was planned that in all the 45 public or private maternity clinics of the north-alpine region, every woman from pilot and control villages coming for delivery should be asked to complete a questionnaire containing sociodemographic, medical, and professional activity items. In addition, the maternity staff had to provide perinatal health data on each birth. They had an alphabetical list of the study villages but to prevent observation bias they did not know which were pilot and which were control. For different reasons, such as staff holidays, maternity clinic reorganisation, or 
Table 2 Descriptive data of the pilot and control samples of women who were questioned in the maternity clinics after delivery

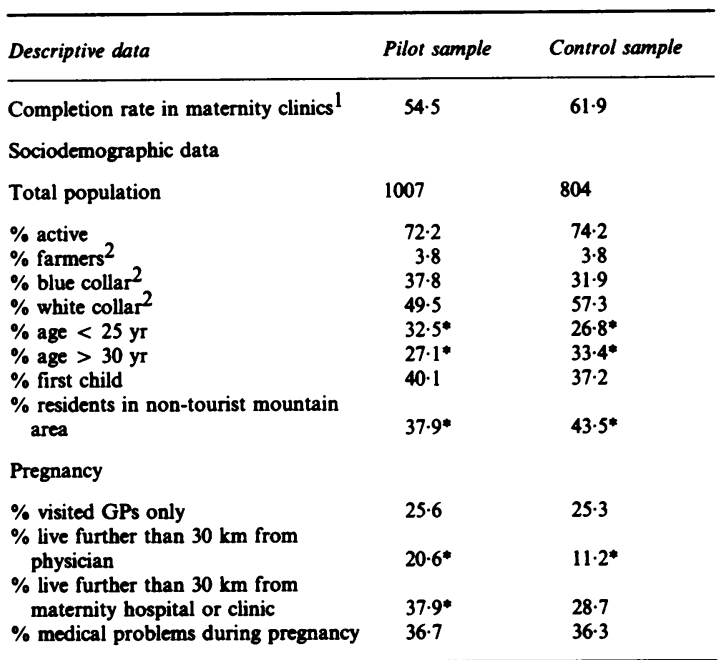

${ }_{1}$ Ratio of questionnaires completed to number of births registered to women from the same study villages

$2 \%$ among active women

-Statistically significant differences $(p<5 \%)$

simply inattention, not all the study women were investigated, resulting in a lack of comparison power. To evaluate this loss to follow up, the maternity registers were checked periodically and data were collected on all the women in the study villages.

\section{Results}

There was a total of 3143 births to women from pilot or control villages in the maternity clinics during the study period. From these, 1811 complete questionnaires were collected $(57.6 \%)$. Table 2 provides data to assess the comparability of the two village categories. The losses to follow-up have yielded differences in the two samples with regard to age (pilot women are younger), geography (control women live more in traditional, non tourist, mountain areas), and distance to the health care providers during pregnancy (pilot women visited more remote physicians). Otherwise the two samples were reasonably similar.

The variables for which a difference is seen between the two zones may well be confounders of the effects one is interested in, since age and distance to health care facilities are known to influence behaviour such as health care search and also perinatal risk. These potential confounders will be controlled for in an analysis using a multivariate logistic model.

The participation of the MCHPS and social workers in the programme can be measured by the proportion of pregnant women in the pilot region who have been

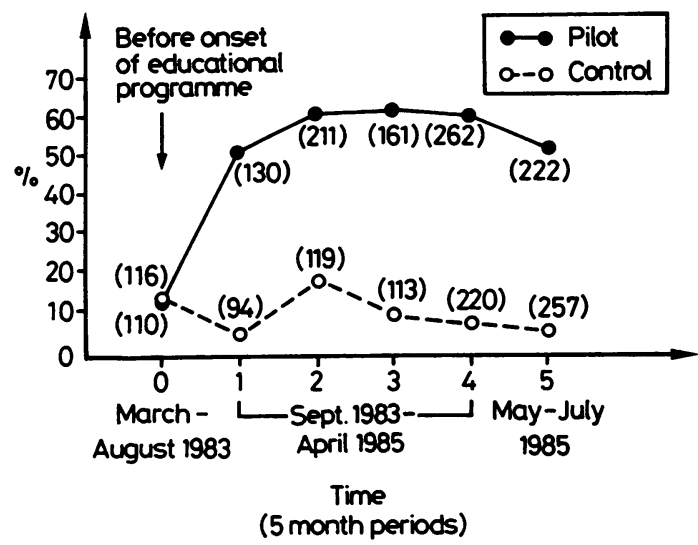

Fig 1 Proportion of pregnant women who were visited at home by the social workers, by study zone and period (number of women).

visited at home and given the educational pamphlets. Figure 1 shows a shift of the "visit rate" soon after the beginning of the programme in the pilot villages, and its stabilisation around $50-60 \%$ during the survey period. In the control villages, the "visit rate" was measured by asking the mothers attending the maternity clinics: it remains about $10 \%$ during the same period; these women were visited for specific social or medical reasons not related to the programme.

The pilot zone private physicians were asked not to alter substantially the way they managed their pregnant women. Therefore, it is difficult to evaluate their involvement in the implementation of the educational programme. Very few attended the meetings that were organised in their area by the MCHPS and social workers. On the other hand, no particular reluctance was noted although they could

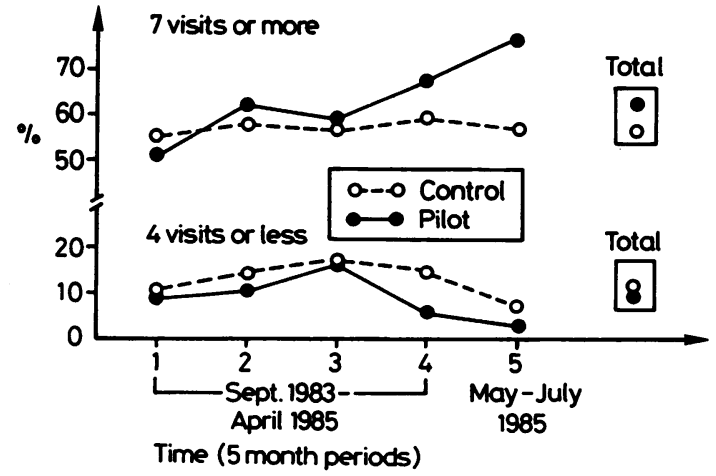

Fig 2 Time trend of the proportion of pregnant women who had high or low frequencies of prenatal care visits, according to the study zones. 
Table 3 Tests for trend for the number of ante-natal visits, according to study zone ${ }^{I}$

\begin{tabular}{llllll}
\hline Zone & $\begin{array}{l}\text { Number of } \\
\text { visits }\end{array}$ & $\begin{array}{l}\text { Slope } \\
(S E)\end{array}$ & $\chi^{2}$ slope & $\chi^{2} 3$ linearity & $\chi^{2} 3$ het. \\
\hline $\begin{array}{l}\text { Unadjusted } \\
\text { data }\end{array}$ & $7+$ & $\begin{array}{l}3 \cdot 1 \cdot 10^{-2} \\
\left(1 \cdot 3 \cdot 10^{-2}\right)\end{array}$ & $5 \cdot 5^{*}$ & $5 \cdot 7 \dagger$ & - \\
Pilot & $4-$ & $\begin{array}{l}-2 \cdot 4 \cdot 10^{-2} \\
\left(8 \cdot 5 \cdot 10^{-3}\right)\end{array}$ & $8 \cdot 0^{* *}$ & $2.4 \dagger$ & - \\
& & $\begin{array}{l}7.8 \cdot 10^{-3} \\
\left(1 \cdot 4 \cdot 10^{-2}\right)\end{array}$ & $0.3 \dagger$ & $0.5 t$ & -
\end{tabular}

Control

$\begin{array}{llllll} & 4- & \begin{array}{c}-5 \cdot 8 \cdot 10^{-3} \\ \left(9 \cdot 5 \cdot 10^{-3}\right)\end{array} & 0.4 \dagger & 7.8 * & - \\ \begin{array}{l}\text { Adjusted } \\ \text { data }\end{array} & 7+ & 5 \cdot 3 \cdot 10^{-2} & 13 \cdot 5 * * * & - & 1 \cdot 7 \dagger\end{array}$

Pilot

$\begin{array}{lllll}4- & -2 \cdot 2 \cdot 10^{-2} & 6 \cdot 7 * * & - & 0 \cdot 4 \dagger \\ 7+ & 2 \cdot 2 \cdot 10^{-2} & 2 \cdot 2 \dagger & - & 0.3 \dagger\end{array}$

Control

$$
4-\quad-4 \cdot 5 \cdot 10^{-3} \quad 0.2 \dagger
$$

$1.6+$

1 This statistical analysis was performed with a programmable calculator, using the programmes written by Rothman and Boice 6

2 Raw data, not controlling for possible confounding

3 Controlling for age of mothers ( \pm 30 years) and distance to physicians who monitored the pregnancies ( $\pm 20 \mathrm{~km}$ )

tNon significant; ${ }^{*} p \leqslant 5 \% ; * * \mathrm{p} \leqslant 1 \% ; * * \mathrm{*} \leqslant 1 \%$.

have resented an interference by public service professionals in their personal relationship with their patients. The occupational physicians did not have much opportunity for any effective preventive action as far as pregnancies were concerned: only one out of five wage earning mothers confirmed that she had been visited at her place of work during her pregnancy.

The educational programme had a positive effect on some behaviours that may influence the course of pregnancy. Specifically, it succeeded in increasing the proportion of women who visited their physician at least once a month in the pilot zone (fig 2). The Mantel extension test ${ }^{45}$ showed a significant positive trend with time, whereas no trend appeared in the control zone (table 3). Conversely, the proportion of women who visited a physician infrequently (at most four visits) is significantly lessened in the pilot region but not in the control one. While pilot zone women visited more remote physicians and were younger, on average, adjusting for these two possible confounders did not substantially alter the preceding results.

The overall proportion of mothers who attended at least four parentcraft sessions in the maternity clinics was also higher in the pilot zone that in the control zone $(\mathrm{OR}=1.3,95 \%$ confidence interval: [1.0-1.6], controlling for age, geographical area, nationality, marital status, and distance of the maternity clinic,
Table 4 Conditions for which no evidence of an educational programme effect was shown

\begin{tabular}{|c|c|c|}
\hline Condition & $\begin{array}{l}\text { Pilot zone } \\
(N=1007)\end{array}$ & $\begin{array}{l}\text { Control zone } \\
(N=804)\end{array}$ \\
\hline $\begin{array}{l}\text { Smoking during pregnancy } \\
\% \text { smoked before programme } \\
\% \text { smoked during programme (mean \%) }\end{array}$ & $\begin{array}{l}18 \cdot 2 \\
18.5\end{array}$ & $\begin{array}{l}15 \cdot 3 \\
17 \cdot 4\end{array}$ \\
\hline $\begin{array}{l}\text { Pregnancy leave of absence } \\
\% \text { stopped at least } 6 \text { weeks } \\
\text { before delivery } 1 \\
\% \text { know duration of after-delivery break }\end{array}$ & $\begin{array}{l}80 \cdot 2 \\
64.8\end{array}$ & $\begin{array}{l}79.8 \\
70.0\end{array}$ \\
\hline $\begin{array}{l}\text { Social services and labour } \\
\% \text { got professional home assistance }{ }^{2} \\
\% \text { were visited by an occupational } \\
\text { physician } \\
\% \text { benefit from reduction of } \\
\text { work time } \\
\% \text { benefit from change of workload }\end{array}$ & $\begin{array}{r}3.8 \\
20 \cdot 4 \\
29 \cdot 3 \\
7.8\end{array}$ & $\begin{array}{r}3 \cdot 8 \\
19 \cdot 2 \\
34 \cdot 0 \\
9 \cdot 0\end{array}$ \\
\hline
\end{tabular}

${ }^{1}$ Among salaried workers; in France they have a right to a minimum of 6 weeks' leave prior to delivery

2 Community family workers may be employed-at minimum cost-to assist pregnant mothers to take care of their other children or in case of illness

3 Only for salaried workers-Labour regulations specify that every pregnant woman should be visited by the occupational physician, and that the time of work should be reduced.

Table 5 Perinatal morbidity in the study rural areas (1983-85 data), in the Rhone-Alpes region, and in France (1981 figures)

\begin{tabular}{lllll}
\hline Perinatal risk & $\begin{array}{l}\text { Pilot } \\
\text { zone } \\
(N=1003)\end{array}$ & $\begin{array}{l}\text { Control } \\
\text { zone } \\
(N=801)\end{array}$ & $\begin{array}{l}\text { Rhône-Alpes } \\
\text { region* }\end{array}$ & France* \\
\hline $\begin{array}{c}\text { \% preterm delivery } \\
(<37 \text { weeks })\end{array}$ & 3.6 & 2.9 & 5.0 & 5.6 \\
$\begin{array}{c}\text { \% low birthweight } \\
(<2500 \mathrm{~g})\end{array}$ & 5.0 & 3.6 & 4.8 & 5.2 \\
\hline
\end{tabular}

*Reference 1

using a main effect logistic model). Inclusion in the model of the distance to the maternity facility did modify the underlined relation between attendance at parentcraft sessions and the study zone, by enhancing the positive effect of the programme.

However, many other behavioural variables showed no effect of the education programme (table 4). It will be noted that this type of programme did not further reduce the proportion of pregnant women who did not stop smoking, given that more than half the women did stop smoking at least during their pregnancy.

In order to provide some insight into the outcome related to these pregnancy behaviours, perinatal morbidity data were compared between the two study groups (table 5). The situation within the north alpine rural area was also compared to that of the entire administrative region to which it belongs (that is, Rhône-Alpes region) and to the equivalent national figures. No difference related to the programme is shown, which is not surprising, given the short time span of the programme. One could even argue that the 
figures are better in the control zone than in the pilot zone. However, an analysis of the time trend of the difference between the two zones reveals that this was the case since the beginning of the programme. What appears clearly, on the other hand, is that the rural data rank very favourably compared to the regional and national data.

\section{Discussion}

The evaluation of community-based prevention programmes poses several methodological problems. ${ }^{7}$ Ideally, data should be collected repeatedly before the programme starts among the pilot and control populations, so as to allow identification of the "natural" time trend of the parameters of interest and to check the comparability of the populations. Similarly, repetitive measurements should be undertaken during the programme implementation in order to check whether the prior trend was modified. In our study, the two target populations were selected so as to be comparable, but, for financial reasons, no data could be collected to assess this comparability prior to the programme implementation; however, given the matching criteria, the similarity of the two zones seems reasonable. Thereafter it has been assumed that the general time trends of perinatal morbidity and of care search behaviour prior to the programme were alike in the two zones.

The differing rate of completion of questionnaires in the maternity clinics between the study zones jeopardises the similarity of the two samples. Observation bias might have occurred if women from the pilot or control zones were not questioned in a similar manner. However, the maternity staff who delivered and collected the questionnaires were not aware of who was assigned to the control or pilot group, and both groups were present in each hospital or clinic. It remains that the design and implementation of the study make it difficult to know exactly whether the two samples were truly comparable. Residual confounding by some unidentified variable may always exist; however, both design-matching and statistical control of known or suspected confounders (through Mantel-Haenszel procedure or multivariate model adjustment) should have resolved this issue.

Generalisation of our results is limited by many factors. Firstly, of course, the general social environment of pregnancy is specific to each country. For instance, the achievement of better antenatal surveillance is promoted in France by the fact that free visits are scheduled during the fourth and fifth months and that all medical prescriptions are free of charge starting from the sixth month of pregnancy. However, most European countries have adopted fairly similar welfare policies as far as antenatal care is concerned. Secondly, the educational means and networks were chosen according to the characteristics of rural areas.

Quite different procedures would have been followed in an urban context, where personal relationships are much looser. Within French rural areas the Northern Alps offer many favourable conditions such as relatively high population and physician densities and efficient communication. The low perinatal morbidity attests for this situation; few French regions (including urban areas) have such low preterm delivery rates*. Further improvements in perinatal morbidity are thus more difficult. This may partially explain the total lack of effect of the programme on perinatal morbidity; other reasons may relate to the time lag between behavioural changes and the induction of health effects. We were aware that the sample sizes and the two years' duration of the programme were liable not to allow the observation of a change in the perinatal morbidity trend, assuming such an educational action was effective to stimulate this change. In addition to the fact that this was not the key objective of the study, the effectiveness of such prevention programmes on perinatal morbidity and mortality have been recently questioned. ${ }^{8-10}$

As to the behavioural variables, it may be interesting to consider two categories. On the one hand, there are factors that are primarily determined (though not exclusively) by the women themselves or by their immediate environment (family, physician), such as smoking habits, prenatal care visits, or attendance at parentcraft sessions. On the other hand, there are those factors that are partially or totally determined by the social environment (labour relationships at the place of work, labour and social security regulations, availability of social or medical services): duration of prenatal leave of absence, occupational physicians' visits, reduction of work load, and professional assistance for work at home belong to this latter category.

The programme has been effective on some of the first category behaviours but not on smoking. Further reduction of smoking among the remaining women who did not stop smoking when they started their pregnancy may require more effective and specific educational means than those involved in our general programme. ${ }^{11-13}$ As to attendance at prenatal visits and parentcraft sessions, it is known that they depend upon the physicians' attitude ${ }^{14}{ }^{15}$; it is reasonable to believe that the pilot region private physicians did favour the efforts that tended to increase recourse to medical care. Incidentally, this may be a condition for their cooperation in such programmes. ${ }^{8}$ But this

*In 1981, preterm delivery rates were 3.0\% in Pays de Loire and Franche-Comté; $3.4 \%$ in Haute-Normandy; 3.6 and $3.7 \%$ in Normandy and Centre regions. It was as high as $8.5 \%$ in Midi-Pyrénées and $9.5 \%$ in Languedoc-Roussillon (1). 
attendance also depends upon the distance to the facilities which influences the willingness of the pregnant women. This was confirmed, in statistical terms, by the fact that adjusting for the distance to the maternity clinics enhanced the positive effect of the programme on attendance at parentcraft classes.

By contrast, no effect could be shown on the second category parameters. This result underscores the fact that educational action alone is limited by many social or environmental conditions. For instance, women's eventual willingness to take longer antenatal leave or to be helped at home by family workers relies on the existence of available services or on the possible replacement of female employees, farmers, or merchants while on maternity leave. Rural areas do not often offer such facilities.

The objective of the programme was not to prove that better information could substitute for social progress. Rather, it aimed at assessing whether better information on hygiene and social rights was liable to induce greater use of the available services and, consequently, create a greater demand for them. This proved unrealistic, at least in the short programme time span.

Social policies and the development of health services should be combined with general health education to further improve perinatal health.

We thank all the social workers and health professionals who implemented the field prevention programme. We are indebted to the mothers who completed the questionnaires in the maternity clinics.

This research was funded by the Regional Health Observatory of Rhône-Alpes and by the Ministry of Health, France. Requests for reprints should be sent to Dr D Zmirou.

\section{References}

${ }^{1}$ Rumeau-Rouquette C, du Mazaubrun C, Rabarison Y. Naître en France-10 ans d'évolution, Doin: Les Editions Inserm, 1984.

${ }^{2}$ Zmirou D. Grossesse, risques et prévention en milieu rural-In: Le jeune enfant-Prévenir, nX, 69-75, 1984.

${ }^{3}$ Robine JM, Maguin P, Nicaud V, Hatton F. Health practices: prenatal care patterns in rural and urban areas. Rev Epidém Santé Publ 1985; 33: 203-11.

${ }^{4}$ Mantel N. Chi-square tests with one degree of freedom: extensions of the Mantel-Haenszel procedure. J Am Stat Assoc 1963; 58: 670-90.

${ }^{5}$ Pearce NE, Cryer PC. Analysis of the components of a linear trend in proportions. Am J Epidemiol 1986; 124: 127-33.

${ }^{6}$ Rothman KJ, Boice JD. Epidemiologic analysis with a programmable calculator. Washington DC: US GPO, 1979.

${ }^{7}$ Salonen JT, Kottke TE, Jacobs DR, Hannan PJ. Analysis of community-based cardiovascular disease prevention studies. Evaluation issues in the North Karelia project and the Minnesota heart health program. Int J Epidemiol 1986; 15: 176-82.

${ }^{8}$ Siegel E, Gillins D, Campbell S, Guild P. A controlled evaluation of rural regional perinatal care: impact on mortality and morbidity. Am J Public Health 1985; 75: 246-53.

${ }^{9}$ Hall MH, Chonk PK, McGillivray I. Is routine antenatal care worthwhile? Lancet 1980; ii: 78-80.

${ }^{10}$ Strachan DP. Antenatal booking and perinatal mortality in Scotland, 1972-1982. Int J Epidemiol 1987; 229-33.

${ }^{11}$ Hebel RJ, Nowicki P, Sexton MJ. The effect of antismoking intervention during pregnancy: an assessment of interactions with maternal characteristics. Am J Epidemiol 1986; 123: 444-54.

12 Windsor RA, Cutter G, Morris J, Reese Y, Manzella B, Bartlett EE, Samuelson C, Spanos D. The effectiveness of smoking cessation methods for smokers in public health maternity clinics: a randomized trial. Am J Public Health 1985; 75: 1389-92.

13 Kleinman JC, Kopstein A. Smoking during pregnancy, 1967-80. Am J Public Health 1987; 77: 823-5.

14 Wollast E, Vandenbussche P, Buekens P. Assessment of antenatal care in Belgium and comparison between public and private medical sectors. Rev Epidém Santé Publ 1986; 34: 52-58.

15 Blondel B, Kaminski M, du Mazaubrun C, RumeauRouquette C. Antenatal care and source of care during pregnancy. Rev Epidém Santé Publ 1982; 30, 21-34.

Accepted for publication January 1988 